\title{
Effect of 45S5 Bio-Glass Particles on Physical Properties and Corrosion Resistance of the Mg-5Zn Matrix Composite
}

\author{
M. A. F. Zaludin*, S. B. Jamaludin*, M. S. Idris, N. A. Llah \\ School of Materials Engineering, Universiti Malaysia Perlis, Perlis, Malaysia \\ Email: aminzaludin90@yahoo.com, ${ }^{*}$ sbaharin@unimap.edu.my
}

Received 24 February 2014; revised 18 March 2014; accepted 25 March 2014

Copyright (C) 2014 by authors and Scientific Research Publishing Inc.

This work is licensed under the Creative Commons Attribution International License (CC BY). http://creativecommons.org/licenses/by/4.0/

c) (i) Open Access

\begin{abstract}
The effect of bio-glass (45S5) addition on the physical properties of Mg-5Zn matrix composite has been investigated. Powder metallurgy method was used to fabricate the composite by mixing, compacting and followed by sintering. Mg-5 wt\% $\mathrm{Zn}$ was reinforced with 5, 10, 15, 20, 25, and 30 wt\% of bio-glass (BG). The physical properties such as density and porosity were determined using a pcynometer. Corrosion resistance was studied by immersion test. The results showed that porosity of the sintered sample decreased for the Mg-5 wt\% Zn reinforced with $5 \mathrm{wt} \%$ of bio-glass. However, above $5 \mathrm{wt} \%$ of bio-glass, the porosity increased. The result also showed that corrosion resistance of $\mathrm{Mg}-5 \mathrm{wt} \% \mathrm{Zn}$ increased as the amount of bio-glass increased.
\end{abstract}

\section{Keywords}

Powder Metallurgy; Bio-Glass; Magnesium; Corrosion; Density; Porosity

\section{Introduction}

Recently, there is a growing trend towards using composite materials, in order to achieve better performance in engineering materials [1]. Currently, magnesium matrix composite is one of the composite materials that have been focused to be used as biomaterials. Various elements are alloyed with magnesium to slow down the degradation rates and to make magnesium alloys competent enough to be applied as biomaterials [2]-[8]. Magnesiumbased composites continue to receive more attention in biomedical application due to their bio-degradability properties. Most of the studies have been carried out to understand the in-vitro and in-vivo degradation behavior of magnesium alloys. Previous studies have been focused toward exploring the possibility of using magnesium

*orresponding authors. 
alloys as biomaterials to avoid follow-up surgery [4] [9]. Another group of biomaterials used in biomedical application is bioactive materials such as ceramic and bio-glass. This group is able to rebuild a bone tissue. Reinforcements such as hydroxyapatite (HAp) and fluoroapatite (FAp) are added into magnesium based alloy to improve bioactivity behavior [9] [10]. Several bioactive materials, such as bio-glass, fluorapatite and wollastonite have already been studied with metals and alloys [11]. Another important factor to produce magnesium matrix composite is fabrication technique. Magnesium matrix composites can be produced via casting and powder metallurgy. Casting is expensive because it needs more energy. Powder metallurgy is a good technique because of the low processing temperature than the casting technique. Interaction between the matrix and the reinforcement can be avoided especially in the case of magnesium [12] [13]. Therefore, this paper reports on the microstructure, physical properties and corrosion resistance of the composite Mg-5 wt\% Zn filled with 4S5S bio-glass particles.

\section{Experimental procedures}

The raw materials used in this work were magnesium powder $(177.05 \mu \mathrm{m}$ size) purity $99.8 \%$ supplied by the Strem Chemicals, USA, zinc powder (307.87 $\mu \mathrm{m}$ size) purity $99.999 \%$ was supplied by the Acros Organics and $45 S 5$ bio-glass powder was supplied by the Biomimetic PTY. LTD. Australia. Zinc powder was firstly ball milled for 3 hours using 10:1 ball to powder ratio at $153 \mathrm{rpm}$ in order to reduce the size of the zinc powder to $225.61 \mu \mathrm{m}$. Milling process could produce homogeneous microstructure in powder metallurgy parts [14] [15]. Then, all raw materials were roll milled for 1 hour and then pressed at $500 \mathrm{MPa}$. The composition of the samples is shown in Table 1. The green compacts were sintered at $430^{\circ} \mathrm{C}$ for 3 hours under an inert environment. Microstructures were observed using an optical microscope (Model: Olympus BX41M) and a Scanning electron microscope (Model: JEOL JSM-6460LA).

The theoretical density was calculated using the rule of mixture

$$
\rho_{\text {Theory }}=\sum\left(\rho_{i} f_{i}\right)
$$

where: $\rho_{i}$-theoretical density of composite constituent; $f_{i}$-mass fraction of composite constituent.

The bulk density was determined using Equation (2) [16].

$$
\rho_{\text {Bulk }}=\text { mass/volume }
$$

True density of the sintered samples was determined using the gas pycnometer (Model: Micromeritics AccuPyc II 1340) according to the ASTM B923-10 [17]. The relative density and total porosity were determined using Equations (3) [16] and (4) [18], respectively.

$$
\begin{gathered}
\rho_{\text {Relative }}=\left(\rho_{\text {Bulk }} / \rho_{\text {theoretical }}\right) \times 100 \\
\text { Total porosity }=\left[\left(\rho_{\text {True }}-\rho_{\text {Bulk }}\right) / \rho_{\text {True }}\right] \times 100
\end{gathered}
$$

\begin{tabular}{|c|c|}
\hline Composites Name & Composition \\
\hline Mg-5Zn & Mg 95 wt\%, Zn 5 wt\% \\
\hline Mg-5Zn/5BG & Mg 90 wt\%, Zn 5 wt\%, BG 5 wt $\%$ \\
\hline Mg-5Zn/10BG & Mg 85 wt\%, Zn 5 wt\%, BG 10 wt\% \\
\hline Mg-5Zn/15BG & Mg 80 wt $\%$, Zn 5 wt\%, BG 15 wt\% \\
\hline Mg-5Zn/20BG & Mg 75 wt $\%$, Zn 5 wt $\%$, BG 20 wt $\%$ \\
\hline Mg-5Zn/25BG & Mg 70 wt $\%$, Zn 5 wt $\%$, BG 25 wt\% \\
\hline Mg-5Zn/30BG & Mg 65 wt\%, Zn 5 wt\%, BG 30 wt\% \\
\hline
\end{tabular}

The immersion test was conducted to determine the corrosion rate of the Mg-5Zn/BG composites inside simulated body fluid (SBF). SBF solution was prepared according to Kokubo and Takadama procedure. The sample dimension was $12 \mathrm{~mm}$ diameter and $7 \mathrm{~mm}$ height. The samples were prepared and immersed according to 
the Standard Guide for Laboratory Immersion Corrosion Testing of Metals (ASTM NACE TM0169/G31-12a) [19]. The samples were grinded up to 1200 grit paper and cleaned ultrasonically with ethanol at $50 \mathrm{MHz}$ for 10 minutes prior to the test. The samples were immersed for 24, 72, 120, and 168 hours and the corrosion rates were evaluated. After different time intervals, the samples were cleaned and dried according to the Standard Practice for Preparing, Cleaning, and Evaluating Corrosion Test Specimens (ASTM G1-03) [20]. The samples were rinsed with distilled water, and let to dry in air. Then, the sample was cleaned using $180 \mathrm{~g} / \mathrm{l}$ chromic acid to remove the corrosion products from its surface and followed by rinsed with ethanol and distilled water [21]. The sample then once more was dried in air and its mass was taken. The corrosion rate was calculated using the Equation (5)

$$
C R=W / A t
$$

where, $C R$ is corrosion rate $\left(\mathrm{mg} / \mathrm{cm}^{2} / \mathrm{h}\right), W$ is mass loss $(\mathrm{mg}), A$ is surface area exposed to the corrosive media $\left(\mathrm{cm}^{2}\right.$ ), and $t$ is the exposure time (hours). Finally, the corrosion product on the sample surface was characterized by the XRD (Model: Bruker D2 Phaser). The scanning range was set from $10^{\circ}$ to $90^{\circ}$.

\section{Results and Discussion}

Figure 1 shows the microstructure of the composites observed under an optical microscope. It can be observed that BG is distributed in the matrix Mg-Zn and segregated along the grain boundaries of Mg-Zn matrix. Similar results also been reported in previous studies [3]. Several pores can be seen in the samples which may be originating from entrapment of environmental gas into the sample during mixing and pressing or shrinkage of composites after the sintering process [3] [10]. Large particle of zinc can be seen in the vicinity area between the BG and the matrix as shown in Figures 1(a), (b), and (d). There are gaps occurring at the interface of Mg-Zn matrix and BG (Figure 1(d)). The gaps occurred due to the presence of harder particles which is BG [10] [20] [21]. It was reported that BG particles hindered the densification of composites during pressing or compaction stage [20]-[23]. The process starts through the softer Mg-Zn matrix flows under compression before consolidation, while BG hindering the consolidation process, hence the gaps will be created. Sintering process also contributes to the occurrence of gaps surrounding BG. Note that, for metal matrix composites, there are three types of in-
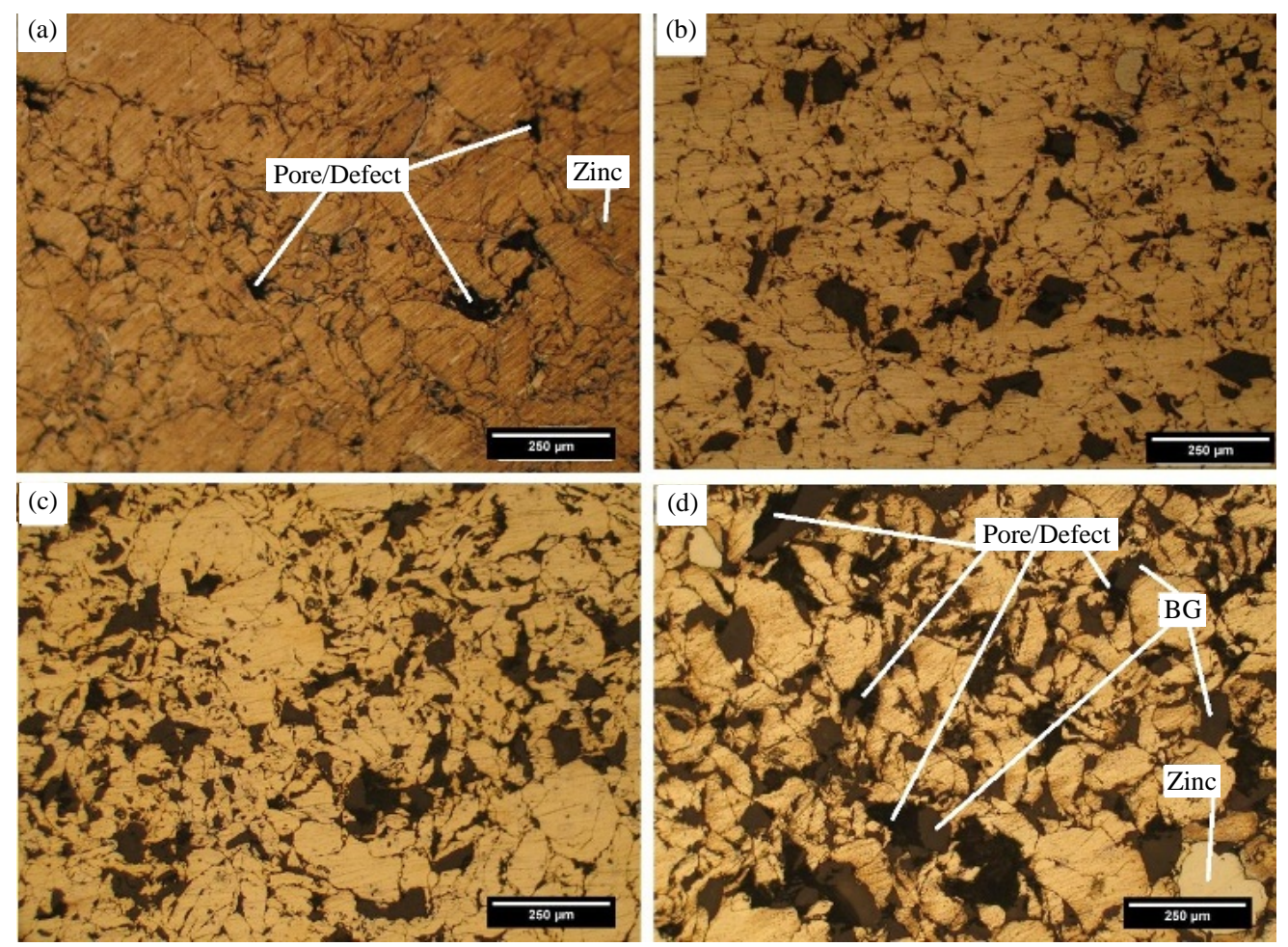

Figure 1. Microstructure of (a) Mg-5Zn; (b) Mg-5Zn/10BG; (c) Mg-5Zn/20BG; and (d) Mg-5Zn/30BG. 
ter-particle contact; 1) metal-metal contact 2) ceramic-ceramic contact 3) metal-ceramic contact. All three types of the inter-particle contacts follow the different contact law for perfectly sintering process. Metal-metal contact uses diffusion and surface energy principle to sinter. Ceramic-ceramic contact sinters due to the elastic properties of the ceramic phase, while metal-ceramic contact sintered are governed by the viscous nature of metals in contact [24]. In this present study, Mg-Zn matrix shows good bonding and well adhered between grains (Figures 1(a) and (d)). However, when in contact with BG, the only bond between Mg-Zn matrix and BG is subjected to the viscous flow of the matrix due to the heat from sintering process [24]. As reported [24], for an area made up mostly of metal, the inter-particles necking between powder particles are well developed due to the diffusion of metallic particles, while for an area made up of metal and ceramic, there are no inter-particles reactions [24]. This result showed that the bond between Mg-Zn and BG is made up by the viscous flow of Mg-Zn adhered to the BG inclusions. The gap area surrounding BG may also occur due to grinding and polishing process. BG is amorphous, therefore when the samples are subjected to abrasive grinding paper or diamond paste polishing, the BG are torn away [24]. Figure 2 shows the microstructure of Mg-Zn/15BG that observed under SEM. The point analysis of 009, 010 and 011 by EDS indicates the phase of Zn, BG and Mg respectively.

Table 2 shows the density of the samples. On the whole, as the amounts of BG increase, the densities of the
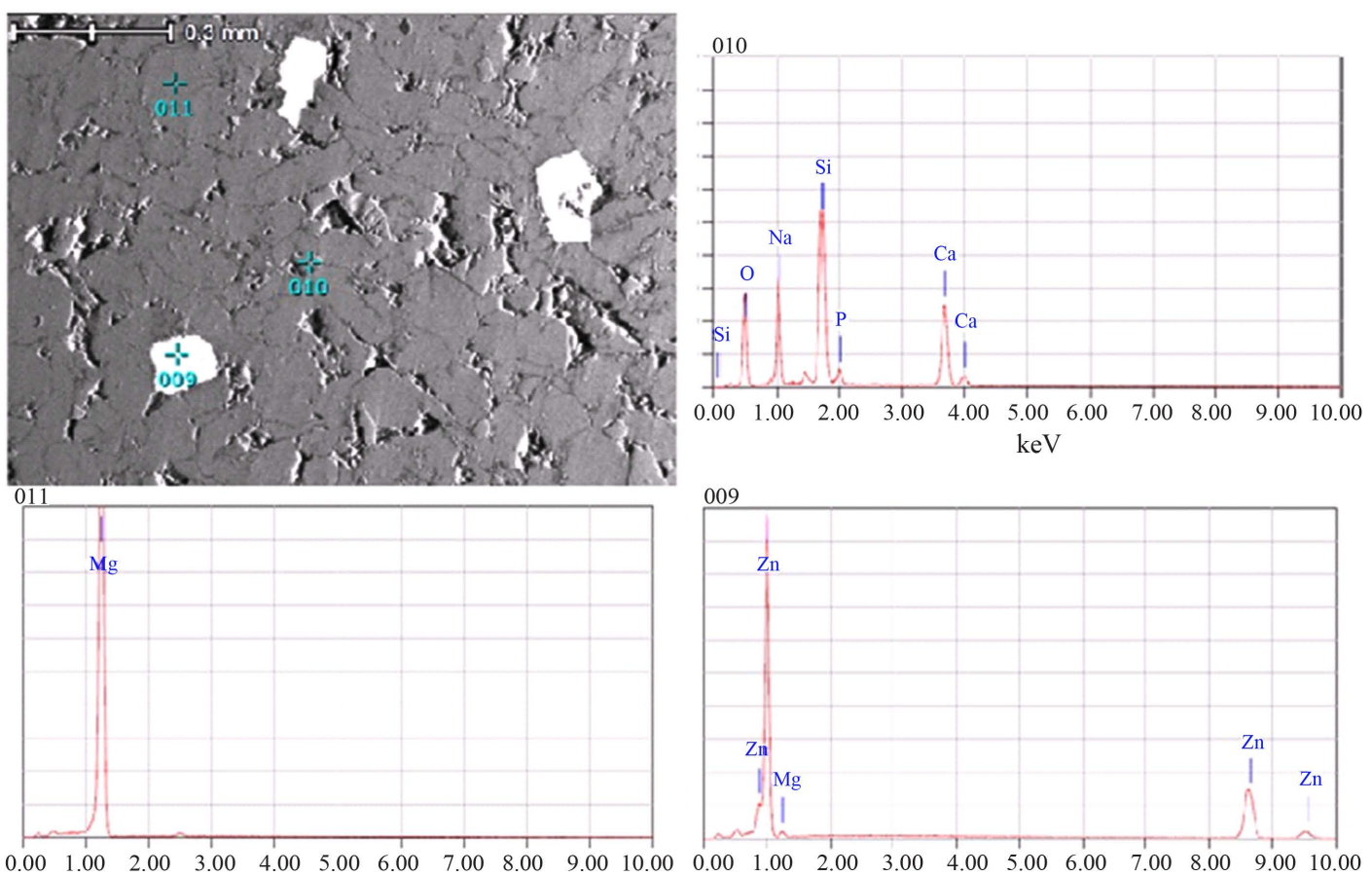

Figure 2. SEM/EDS of Mg-5Zn/15BG composite.

Table 2. The densities of the samples

\begin{tabular}{cccccc}
\hline Sample & $\begin{array}{c}\text { Theoretical Density } \\
\left(\mathrm{g} / \mathrm{cm}^{3}\right)\end{array}$ & $\begin{array}{c}\text { Bulk Density } \\
\left(\mathrm{g} / \mathrm{cm}^{3}\right)\end{array}$ & $\begin{array}{c}\text { True Density } \\
\left(\mathrm{g} / \mathrm{cm}^{3}\right)\end{array}$ & $\begin{array}{c}\text { Relative Density } \\
(\%)\end{array}$ & $\begin{array}{c}\text { Total Porosity } \\
(\%)\end{array}$ \\
Mg-5Zn & 1.8086 & 1.6726 & 1.8032 & 92.4804 & 7.2427 \\
Mg-5Zn/5BG & 1.8390 & 1.7100 & 1.8148 & 92.9853 & 5.7747 \\
Mg-5Zn/10BG & 1.8704 & 1.7243 & 1.8524 & 92.1889 & 6.9153 \\
Mg-5Zn/15BG & 1.9028 & 1.7456 & 1.8911 & 91.7385 & 7.6939 \\
Mg-5Zn/20BG & 1.9364 & 1.7512 & 1.9134 & 90.4359 & 8.4771 \\
Mg-5Zn/25BG & 1.9713 & 1.7847 & 1.9625 & 90.5342 & 9.4658 \\
Mg-5Zn/30BG & 2.0074 & 1.7992 & 1.9885 & 89.6284 & 9.5197 \\
\hline
\end{tabular}


composites also increase. The trend of the result is valid for all theoretical, bulk and true densities. The theoretical density is almost accurate with the true density of the composites. However, the trends show that as the amounts of BG increase, the relative density decreases. The highest relative density obtained is for Mg-5Zn/5BG which is $92.99 \%$. When the amount of BG exceeds $5 \mathrm{wt} \%$, the relative density of the composites is decreasing. Consequently, the Mg-5Zn/5BG also has the lowest percentage of total porosity. As a result, when the amount of BG increases, the porosity is also increases. This argument is supported by the microstructure results as shown in Figure 1, as the amount of BG increase, the gaps or pore portions are also increased. The increasing amounts of harder BG particles in the matrix hindered the consolidation process of the composite. However, in the case of biomaterials, porosity is favored for facilitating the cell reorganizations and vascularization when applied inside physiological environment [10].

Figure 3 shows the corrosion rate of the composites inside SBF. The corrosion mechanism of the samples is described according to the following reactions [22] [23]

Oxidation reaction:

$$
\mathrm{Mg} \rightarrow \mathrm{Mg}^{2+}+2 \mathrm{e}^{-}
$$

Reduction reaction:

$$
2 \mathrm{H}_{2} \mathrm{O}+2 \mathrm{e}^{-} \rightarrow 2 \mathrm{OH}^{-}+\mathrm{H}_{2}
$$

As the magnesium is immersed inside the SBF, the $\mathrm{Cl}^{-}$ions will react with the samples. The reactions of $\mathrm{Cl}^{-}$ ions with magnesium and $\mathrm{Mg}(\mathrm{OH})_{2}$ layers are presented by Equations (7) and (8) [22] [23].

$\mathrm{Cl}^{-}$in contact with $\mathrm{Mg}$ samples:

$$
\mathrm{Mg}(\mathrm{s})+2 \mathrm{Cl}^{-}(\mathrm{aq}) \rightarrow \mathrm{MgCl}_{2}+2 \mathrm{e}^{-}
$$

$\mathrm{Cl}^{-}$in contact with $\mathrm{Mg}(\mathrm{OH})_{2}$ layers:

$$
\mathrm{Mg}(\mathrm{OH})_{2}(\mathrm{~s})+2 \mathrm{Cl}^{-}(\mathrm{aq}) \rightarrow \mathrm{MgCl}_{2}+2 \mathrm{OH}^{-}
$$

Magnesium corrosion process overall are denoted by Equation (9).

$$
\mathrm{Mg}(\mathrm{s})+2 \mathrm{H}_{2} \mathrm{O}(\mathrm{l}) \rightarrow \mathrm{Mg}(\mathrm{OH})_{2}(\mathrm{~s})+\mathrm{H}_{2}(\mathrm{~g})
$$

It could be observed that as the immersion time prolonged, the corrosion rates decreased. This argument is valid for all compositions of the composites. For Mg-5Zn, the corrosion rate is the highest compared to other compositions. At the third day of immersions, the samples are shattered into powders and the corrosion rate of this composition could only be taken up to this time intervals.

The lowest corrosion rates are given by the Mg-5Zn/15BG, which is $1.30,0.46,0.41$, and $0.42 \mathrm{mg} / \mathrm{cm}^{2} \cdot \mathrm{hr}$ af-

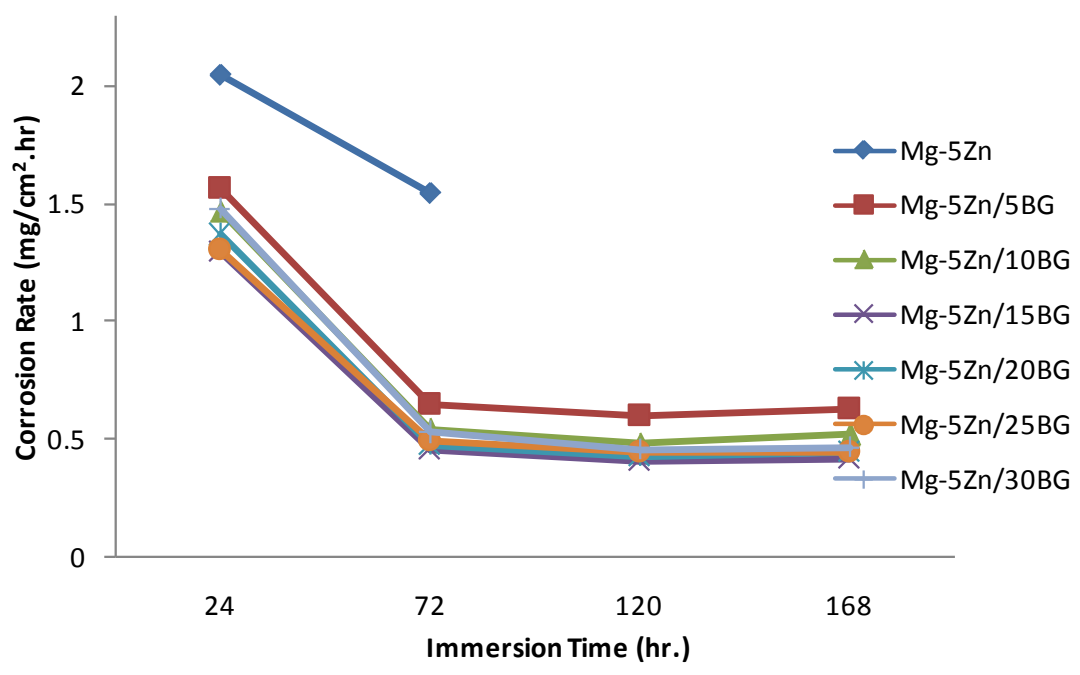

Figure 3. Corrosion rate of the composites immersed inside SBF. 
ter 24, 72, 120, and $168 \mathrm{hr}$. of immersion respectively. However, when the amount of BG content exceeds $15 \mathrm{wt} \%$ of BG, the corrosion rates increased, but the rates are still comparable with Mg-5Zn/15BG. From Figure 3, it could be seen that the greatest dropped of the corrosion rate for all samples occurs between 24 to $72 \mathrm{hr}$ of immersion. The largest amount of corrosion rate dropped (64.96\%) is experienced by the Mg-5Zn/20BG, while the lowest amount of corrosion rate dropped (24.39\%) is given by the Mg-5Zn. As the immersion time is prolonged after $72 \mathrm{hr}$, the corrosion rates of all samples tend to be stable.

Figure 4 shows the $\mathrm{pH}$ of the SBF during immersion. The starting value of the $\mathrm{pH}$ solution is 7.4. As the immersion time prolonged, the $\mathrm{pH}$ of the solution increased. At $24 \mathrm{hr}$ of immersion, Mg-5Zn indicating the highest $\mathrm{pH}$ values compared to other samples, followed by the Mg-5Zn/5BG. The $\mathrm{pH}$ continues to increase until $72 \mathrm{hr}$. of immersion. The $\mathrm{pH}$ shows stable trends after 3 days of immersions. Figure 5 shows the diffraction pattern of the corrosion products on the Mg-5Zn/15BG after 7 days of immersion. It shows well defined peak for $\mathrm{Mg}$ and $\mathrm{Mg}(\mathrm{OH})_{2}$, while for apatite, $\mathrm{Ca}_{10}\left(\mathrm{PO}_{4}\right)_{6}(\mathrm{OH})_{2}$ the peak could still be observed at $33^{\circ}$. The difficulties in monitoring the $\mathrm{CaP}$ peak are due to its amorphous nature.
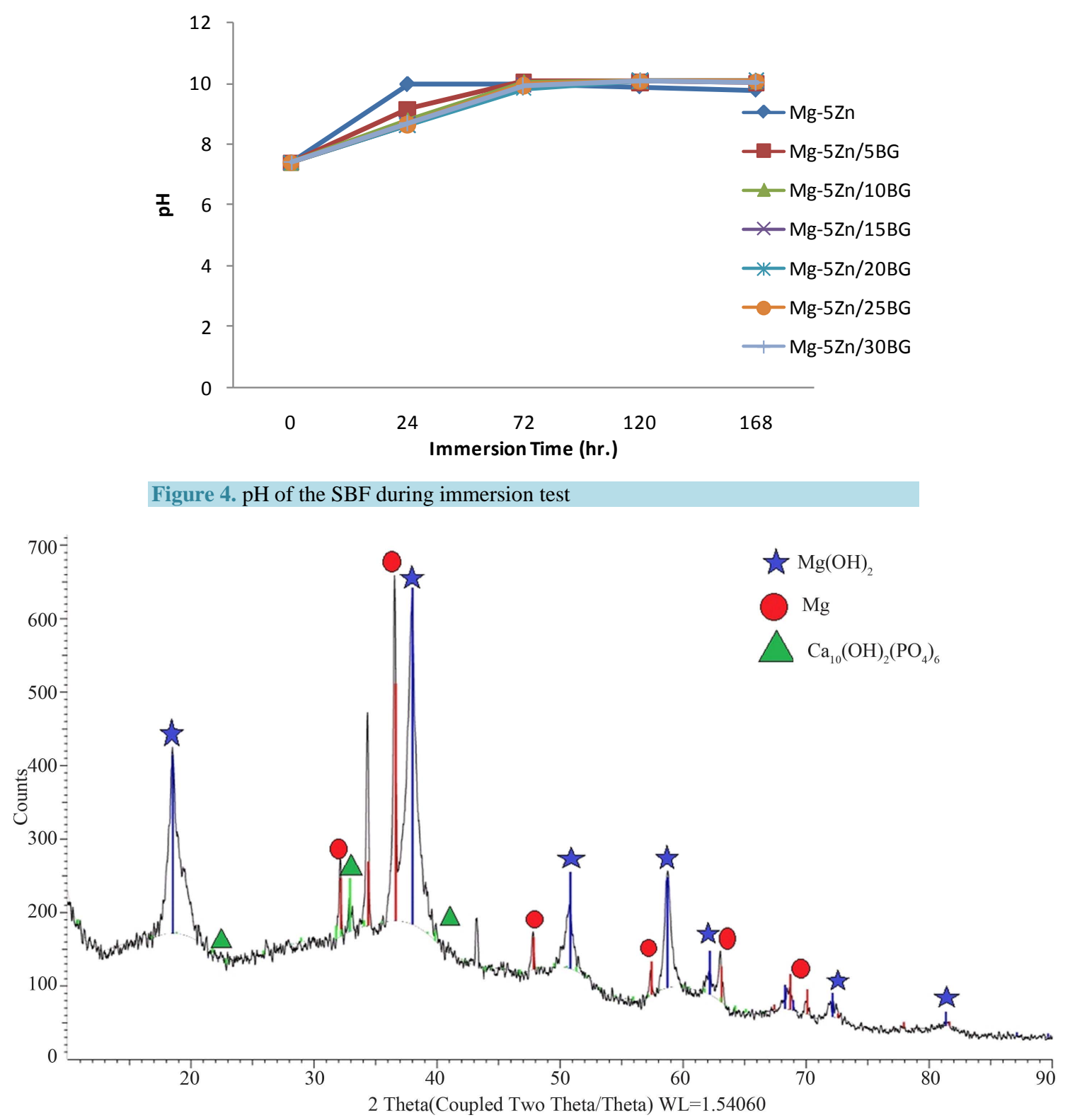

Figure 5. Diffractogram of precipitation on Mg-5Zn/15BG surface after 7 days of immersion 
Large dropped in corrosion rate of the samples is due to the formation of protective CaP layer. It is suggested that the BG will partially dissolved inside SBF and governed the development of protective CaP layers [3]. Besides, the $\mathrm{Mg}(\mathrm{OH})_{2}$ layer is also suggested helped to lowered the corrosion rate. The increase corrosion rate of the samples with amount greater than $15 \mathrm{wt} \%$ may be subjected to the porosity of the composites. It could be observed that for 20,25 and $30 \mathrm{wt} \%$ of BG, the total porosity are greater than $8 \%$. It is suggested that when the amount of porosity are above than $8 \%$, the corrosion rate are increased due to increase amount of surface area. The increase surface area will provide more venues for the corrosion process to take place [24] [25]. The $\mathrm{pH}$ of the solution are increasing due to the interaction of $\mathrm{Mg}(\mathrm{OH})_{2}$ layers with the $\mathrm{Cl}^{-}$ions from SBF. These reactions are denoted in Equation (8). From Equation (8), it could be seen that the products of these reactions are $\mathrm{OH}^{-}$ which is responsible for the increase of $\mathrm{pH}$ of the solution. It is proposed that as the $\mathrm{pH}$ of the solution are high $(>9)$, it promotes the nucleation of ions such as $\mathrm{PO}_{4}^{3-}, \mathrm{OH}^{-}$, and $\mathrm{Ca}^{2+}$ into the samples surface, forming $\mathrm{CaP}$ layers. Besides, the supersaturated condition of the SBF solution towards those ions will also helped the nucleation process [26]-[28].

\section{Conclusions}

1) The Mg-5Zn/BG composite has been successfully produced by powder metallurgy. Bio-glass is distributed in the Mg-Zn matrix, and it was segregated at the grain boundaries as the amount of BG increased.

2) The increased amount of BG hindered the densification of the Mg-5Zn matrix, thus producing defects or gaps between $B G$ and the matrix.

3) Mg-5Zn/BG composites degraded inside SBF and the porosity has a significant role in influencing the corrosion rate.

4) As the immersion time prolonged, the corrosion rate decreased due to the formation of protective $\mathrm{Mg}(\mathrm{OH})_{2}$ and $\mathrm{CaP}$ layers.

5) Mg-5Zn/15BG showed the greatest corrosion resistance compared to other samples. However, Mg-5Zn/20, 25, and $30 \mathrm{wt} \%$ also have corrosion resistance comparable with Mg-5Zn/15BG.

\section{Acknowledgements}

The authors acknowledge the grant provided under the Science Fund (03-01-15-SF0159) from the MOSTI Malaysia to carry out this research.

\section{References}

[1] Mohammed, M.M.M., Elkady, O.A. and Abdelhameed, A.W. (2013) Effect of Alumina Particles Addition on PhysicoMechanical Properties of AL-Matrix Composites. Open Journal of Metal, 3, 72-79. http://dx.doi.org/10.4236/ojmetal.2013.34011

[2] Gu, X., Zheng, Y., Cheng, Y., Zhong, S. and Xi, T. (2009) In Vitro Corrosion and Biocompatibility of Binary Magnesium Alloys. Biomaterials, 30, 484-498. http://dx.doi.org/10.1016/j.biomaterials.2008.10.021

[3] Huan, Z.G., Leeflang, M.A., Zhou, J. and Duszczyk, J. (2011) ZK30-Bioactive Glass Composites for Orthopedic Application: A Comparative Study on Fabrication Method and Characteristics. Materials Science and Engineering B, 20, 1644-1652. http://dx.doi.org/10.1016/j.mseb.2011.07.022

[4] Zainal Abidin, N.I., Martin, D. and Atrens, A. (2011) Corrosion of High Purity Mg, AZ91, ZE41 and Mg $\mathrm{Zn}_{0.2} \mathrm{Mn}$ in Hank’s Solution at Room Temperature. Corrosion Science, 53, 862-872. http://dx.doi.org/10.1016/j.corsci.2010.10.008

[5] Zhang, X., Yuan, G., Mao, L., Niu, J. and Ding, W. (2012) Biocorrosion Properties of As-Extruded Mg-Nd-Zn-Zr Alloy Compared with Commercial AZ31 and WE43 Alloys. Materials Letters, 66, 209-211. http://dx.doi.org/10.1016/j.matlet.2011.08.079

[6] Witte, F., Hort, N., Vogt, C., Cohen, S., Kainer, K.U., Willumeit, R. andFeyerabend, F. (2008) Degradable Biomaterials Based on Magnesium Corrosion. Current Opinion in Solid State and Materials Science, 12, 63-72. http://dx.doi.org/10.1016/j.cossms.2009.04.001

[7] Song, G. (2007) Control of Biodegradation of Biocompatible Magnesium Alloys. Corrosion Science, 49, $1696-1701$. http://dx.doi.org/10.1016/j.corsci.2007.01.001

[8] Staiger, M.P., Pietak, A.M., Huadmai, J. and Dias, G. (2006) Magnesium and Its Alloys as Orthopedic Biomaterials: A Review. Biomaterials, 27, 1728-1734. 
http://dx.doi.org/10.1016/j.biomaterials.2005.10.003

[9] Razavi, M., Fathi, M.H. and Meratian, M. (2010) Bio-Corrosion Behavior of Magnesium-Fluorapatite Nanocomposite for Biomedical Applications. Materials Letters, 64, 2487-2490. http://dx.doi.org/10.1016/j.matlet.2010.07.079

[10] Jurczyk, M.U., Jurczyk, K., Miklaszewski, A. and Jurczyk, M. (2011) Nanostructured Titanium-45S5 Bioglass Scaffold Composites for Medical Applications. Materials and Design, 32, 4882-4889 http://dx.doi.org/10.1016/j.matdes.2011.06.005

[11] Jamaludin, S.B., Adzali, N.M.S. and Derman, M.N. (2014) Microstructure and In-Vitro Test Bioactivity Behavior of co-cr-mo (f-75)/Hydroxyapatite in Phosphate Buffered Saline Solution. Acta Metallurgica Slovaca, 20, 82-88.

[12] Rahimian, M., Ehsani, N., Parvin, N. and Baharvandi, H.R. (2009) The Effect of Particle Size, Sintering Temperature and Sintering Time on the Properties of $\mathrm{Al}_{-} \mathrm{Al}_{2} \mathrm{O}_{3}$ Composites, Made by Powder Metallurgy. Journal of Materials Processing Technology, 209, 5387-5393. http://dx.doi.org/10.1016/j.jmatprotec.2009.04.007

[13] Varol, T. and Canakci, A. (2013) Effect of Particle Size and Ratio of $\mathrm{B}_{4}$ C Reinforcement on Properties and Morphology of Nanocrystalline Al2024-B $\mathrm{B}_{4} \mathrm{C}$ Composite Powders. Powder Technology, 246, 462-472. http://dx.doi.org/10.1016/j.powtec.2013.05.048

[14] Xu, X., Huang, L., Liu, X. and Fu, X. (2002) Effects of $\alpha / \beta$ Ratio in Starting Powder on Microstructure and Mechanical Properties of Silicon Nitride Ceramics. Ceramics International, 28, 279-281. http://dx.doi.org/10.1016/S0272-8842(01)00091-8

[15] Slipenyuk, A., Kuprin, V., Milman, Yu., Spowart, J.E. and Miracle, D.B. (2004) The Effect of Matrix to Reinforcement Particle Size Ratio (PSR) on the Microstructure and Mechanical Properties of a PM Processed AlCuMn/SiCp MMC. Materials Science and Engineering A, 381, 165-170. http://dx.doi.org/10.1016/j.msea.2004.04.040

[16] de Fátima Ferreira Mariotto, S., Guido, V., Liu, Y.C., Soares, C.P. and Cardoso, K.R. (2011) Porous Stainless Steel for Biomedical Applications. Materials Research, 14, 146-154. http://dx.doi.org/10.1590/S1516-14392011005000021

[17] ASTM B923 (2010) Standard Test Method for Metal Powder Skeletal Density by Helium or Nitrogen Pycnometry. Philadelphia: ASTM International. http://dx.doi.org/10.1520/B0923-10

[18] Askeland, D.R. and Phulé, P.P. (2008) The Science and Engineering of Materials. International Student Ed., Ohio: Cengage Learning.

[19] ASTM NACE TM0169/G31-12a (2012) Standard Guide for Laboratory Immersion Corrosion Testing of Metals. Philadelphia: ASTM International. http://dx.doi.org/10.1520/G0031-12A

[20] ASTM G1 (2011) Standard Practice for Preparing, Cleaning, and Evaluating Corrosion Test Specimens. Philadelphia: ASTM International. http://dx.doi.org/10.1520/G0001-03R11

[21] Razavi, M., Fathi, M.H. and Meratian, M. (2010) Fabrication and Characterization of Magnesium-Fluorapatite Nanocomposite for Biomedical Applications. Materials Characterization, 61, 1363-1370. http://dx.doi.org/10.1016/j.matchar.2010.09.008

[22] Ghali, E., Dietzel, W. and Kainer, K.U. (2004) General and Localized Corrosion of Magnesium Alloys: A Critical Review. Journal of Materials Engineering and Performance, 13, 7-23. http://dx.doi.org/10.1361/10599490417533

[23] Poinern, G.E.J., Brundavanam, S. and Fawcett, D. (2012) Biomedical Magnesium Alloys: A Review of Material Properties, Surface Modifications and Potential as a Biodegradable Orthopaedic Implant. American Journal of Biomedical Engineering, 2, 218-240. http://dx.doi.org/10.5923/j.ajbe.20120206.02

[24] Čapek, C. and Vojtěch, D. (2013) Properties of Porous Magnesium Prepared by Powder Metallurgy. Materials Science and Engineering C, 33, 564-569. http://dx.doi.org/10.1016/j.msec.2012.10.002

[25] Li, Y.H., Rao, G.B., Rong, L.J., Li, Y.Y. and Ke, W. (2003) Effect of Pores on Corrosion Characteristics of Porous NiTi Alloy in Simulated Body Fluid. Materials Science and Engineering A, 363, 356-359. http://dx.doi.org/10.1016/S0921-5093(03)00629-4

[26] Liu, C., Xin, Y., Tang, G. and Chu, P.K. (2007) Influence of Heat Treatment on Degradation Behavior of Bio-Degradable Die-Cast AZ63 Magnesium Alloy in Simulated Body Fluid. Materials Science and Engineering A, 456, 350357. http://dx.doi.org/10.1016/j.msea.2006.12.020

[27] Zhang, D., Hupa, M. and Hupa, L. (2008) In Situ pH within Particle Beds of Bioactive Glasses. Acta Biomaterialia, 4, 1498-1505. http://dx.doi.org/10.1016/j.actbio.2008.04.007

[28] Zhang, S., Zhang, X., Zhao, C., Li, J., Song, Y., Xie, C., Tao, H., Zhang, Y., He, Y., Jiang, Y. and Bian, Y. (2010) Research on an Mg-Zn Alloy as a Degradable Biomaterial. Acta Biomaterialia, 6, 626-640.

http://dx.doi.org/10.1016/j.actbio.2009.06.028 